\title{
A coevolução entre políticas públicas/instituições e o desenvolvimento tecnológico: o caso da Petrobras Biocombustível
}

\author{
Samuel Façanha Câmara \\ Universidade Estadual do Ceará / Programa de Pós-Graduação em Administração \\ Fortaleza / CE - Brasil
}

Alexander Brasil

Universidade Estadual do Ceará / Mestrado em Administração

Fortaleza / CE - Brasil

\begin{abstract}
O presente trabalho teve como objetivo principal analisar a coevolução das políticas públicas/instituições e das capacidades tecnológicas da Petrobras Biocombustível (PBio). Para tanto, o estudo considerou uma abordagem teórica associada à corrente neoshumpteriana, analisando sua evolução no período de 2004 até 2012. A análise demonstrou que: i) a PBio/Petrobras alcançou maiores níveis de capacidades tecnológicas em suas rotas industriais se comparadas às tecnologias agrícolas que induziu; e ii) as políticas/instituições do setor evoluíram, principalmente em relação à política industrial de financiamento e à política de estímulo à demanda. Entretanto, os níveis das políticas/instituições, embora elevados no setor, não estabeleceram níveis tecnológicos de fronteira internacional, indicando que esse salto se dará por meio de mais esforços internos.
\end{abstract}

Palavras-chave: inovação; evolução tecnológica; biodiesel; biocombustíveis; coevolução.

La coevolución entre las políticas públicas/instituciones y desarrollo tecnológico: el caso de la Petrobras Biocombustível

Este estudio tuvo como objetivo analizar la coevolución de las políticas públicas/ instituciones y las capacidades tecnológicas de Petrobras Biocombustível (PBio). Para eso, el estudio consideró un enfoque teórico asociado con la corriente neoshumpteriana, analizando su evolución desde 2004 a 2012. El análisis mostró que: i) PBio/Petrobras alcanzó niveles más altos de las capacidades tecnológicas en sus rutas industriales en comparación con las tecnologías agrícolas que indujo; y ii) las políticas/instituciones del sector evolucionaron, principalmente con relación a la política industrial de la financiación y la

DOI: http://dx.doi.org/10.1590/0034-7612136192

(c) (1)

Artigo recebido em 10 jun. 2014 e aceito em 30 jun. 2015.

Os autores agradecem ao professor Paulo N. Figueiredo, da FGV-Ebape, pelas valiosas orientações e sugestões, e à Capes, pelas bolsas de estudo que possibilitaram a dedicação necessária para a realização deste trabalho. 
política de estímulo a la demanda. Sin embargo, los niveles de políticas/instituciones, aunque alto en el sector, no establecieron niveles tecnológicos de frontera internacional, lo que indica que este salto será mediante más esfuerzos internos.

Palabras clave: innovación; desarrollos tecnológicos; biodiesel; biocombustibles; coevolución.

The coevolution between public policies/institutions and technological development: the case of Petrobras Biocombustível

The main objective of this paper was to analyze the coevolution of the public policies/institutions and technological capabilities of Petrobras Biocombustivel (PBio). To do so, the study considered a theoretical approach related to the neoshumpterian view, analyzing the evolution process from 2004 to 2012. The main findings were: i) PBio/Petrobras reached higher levels of technological capabilities in their industrial paths when compared to induced agricultural technologies; and, ii) the policies/ institutions of this sector have evolved, especially regarding the financing industrial policy and the demand raising policy. However, although the levels of policies/institutions were high in the sector, they do not established technological patterns of international frontier, indicating that this catching up will be reached through additional internal efforts.

KEYWORDs: innovation; technologic evolution; biodiesel; biofuels; coevolution.

\section{Introdução}

A literatura sobre inovação de uma forma geral, e em específico a que diz respeito aos países em desenvolvimento, tem se preocupado com o efeito das políticas públicas e das instituições sobre as empresas e suas trajetórias tecnológicas (Lall e Teubal, 1998; Lall, 2013; Avnimelech e Teubal, 2008; Latsch, 2008). Desse modo, faz sentido considerar que essas políticas/ instituições e suas relações com as empresas nos países das chamadas economias emergentes ocorrem de forma mais frequente e intensa, principalmente nos casos das especificidades das indústrias nascentes desses países (Bell, Ross-Larson e Westphal, 1984; Deraniyagala, 2001, 2006; Mkandawire, 2007; Cimoli et al., 2006).

As especificidades dessas indústrias se estabelecem, normalmente, a partir de suas trajetórias de evolução tecnológica, considerando o sentido e a velocidade de obtenção de suas capacidades inovadoras, quase sempre como latecomer firms, no mercado internacional. Algumas dessas organizações constroem um caminho que as permite competir com os principais atores mundiais de seus mercados, tanto assimilando conhecimento já produzido nos países desenvolvidos como realizando esforços de melhoria e avanços, estabelecendo trajetórias tecnológicas com características próprias, influenciadas por seu ambiente e, principalmente, pelas políticas/instituições presentes nesses países e ligadas a seus setores (Dosi, Freeman e Fabiani, 1994; Dahlman e Westphal, 1982; Bell e Pavitt, 1993, 1995; Lall, 1992; Kim, 1993; Bell e Figueiredo, 2012).

Nessa vertente, diversos pesquisadores vêm desenvolvendo estudos sobre as políticas públicas de fomento ao processo de evolução tecnológica (i.e.: inovação) em regiões e paí- 
ses de economias emergentes, levando em consideração diferentes aspectos, tais como: a formação e evolução do sistema nacional de inovação; a criação de tipologias das políticas empregadas, seus efeitos no crescimento econômico e no desenvolvimento empresarial; e o processo de coevolução das instituições formadoras e executoras de políticas, todos propondo uma série de frameworks analíticos sobre essas questões (Lall e Latsch, 1998; Avnimelech e Teubal, 2008; Lall, 2013; Švarc, Perkovic e Laznjak, 2011; Krozer e Nentjes, 2008). Alguns desses estudos, inclusive, sugerem a ampliação dessas análises para os mecanismos presentes nas políticas, usando medidas e tipologias adequadas e relacionando-as com a evolução das capacidades inovadoras das empresas, em nível micro, e em indústrias nascentes das economias emergentes (Malik e Kotabe, 2009; Figueiredo, 2008; Lall e Teubal, 1998; Bartels et al., 2012; Jacobsson e Bergek, 2006).

Outros trabalhos, como os de Bell e Figueiredo (2012) e Dieleman e Sachs (2008), afirmam que pouco se sabe sobre o papel das empresas e instituições no processo de aprendizado, de geração de conhecimento e de capacidades tecnológicas em latecomer firms. Assim, há certa carência de estudos empíricos capazes de analisar, propor e testar tipologias e medidas que possam estabelecer o papel das políticas públicas e das instituições voltadas a estimular a evolução tecnológica de setores e de suas empresas constituintes em países de economia emergente. Este trabalho pretende contribuir com a diminuição dessa lacuna por meio do estudo do caso da Petrobras Biocombustível (PBio) e de suas três principais usinas de produção de biodiesel, localizadas na região Nordeste do Brasil (incluindo o norte de Minas Gerais), considerando sua evolução tecnológica e seus fornecedores de matérias-primas, principalmente aqueles ligados à agricultura familiar, bem como o comportamento das políticas públicas e das instituições de fomento a essa indústria.

Diante do exposto, o presente estudo propõe analisar a relação das firmas com o conjunto de políticas públicas/instituições, mix chamado por Teubal (2002) de "policy portfolio", considerando a perspectiva da coevolução juntamente com as capacidades tecnológicas das empresas nos países de economias emergentes, visando, assim, contribuir para o aprimoramento de um instrumento de análise baseado na evolução dos frameworks utilizados por Lall e Teubal (1998), Evans (1995) e Rodrik (1995). O trabalho apresenta como objetivo principal analisar a coevolução das políticas públicas/instituições e as capacidades tecnológicas da PBio e, como objetivos específicos: i) encontrar uma métrica de mensuração de capacidades tecnológicas para a PBio, e; ii) relacionar, coevolucionariamente, as capacidades tecnológicas e as políticas/instituições.

Com o intuito de atender seus propósitos iniciais, este artigo se divide nas seguintes seções: 1) introdução, que apresentou a justificativa para o trabalho por meio de sua relevância e contribuição; 2) referencial e framework analítico, que expõem como as variáveis serão tratadas na análise da coevolução das capacidades tecnológicas e das políticas/instituições; 3) desenho da pesquisa e o método, que mostram como a pesquisa foi estruturada e conduzida no campo; 4) análise dos resultados, que revela, de maneira analítica e individualizada, os achados acerca da evolução das capacidades tecnológicas da PBio e das políticas/instituições 
para, em seguida, relacioná-las de forma coevolucionária; e 5) conclusões, onde serão conduzidas reflexões acerca dos achados e suas peculiaridades com base na pesquisa e no framework utilizado, bem como das limitações do estudo e sugestões para pesquisas futuras.

\section{Evolução das capacidades tecnológicas em latecomer firms}

Este trabalho segue a mesma linha teórica do framework geral concebido por Lall (1992) e adaptado por Bell e Figueiredo (2012), o qual considera que as latecomer firms também evoluem e, em consequência dessa evolução, buscam acumular capacidades tecnológicas até atingir níveis inovativos a partir de suas estratégias e mecanismos de aprendizagem. Tais capacidades impactam o desempenho inovativo e, por conseguinte, levam a resultados econômicos e socioambientais positivos. Esse framework também leva em consideração outras variáveis relevantes na formação das capacidades tecnológicas e do desempenho. Tais variáveis incluem fatores específicos de cada firma, bem como fatores no nível da indústria, das instituições, das políticas públicas, entre outros (figura 1).

Figura 1

Framework conceitual

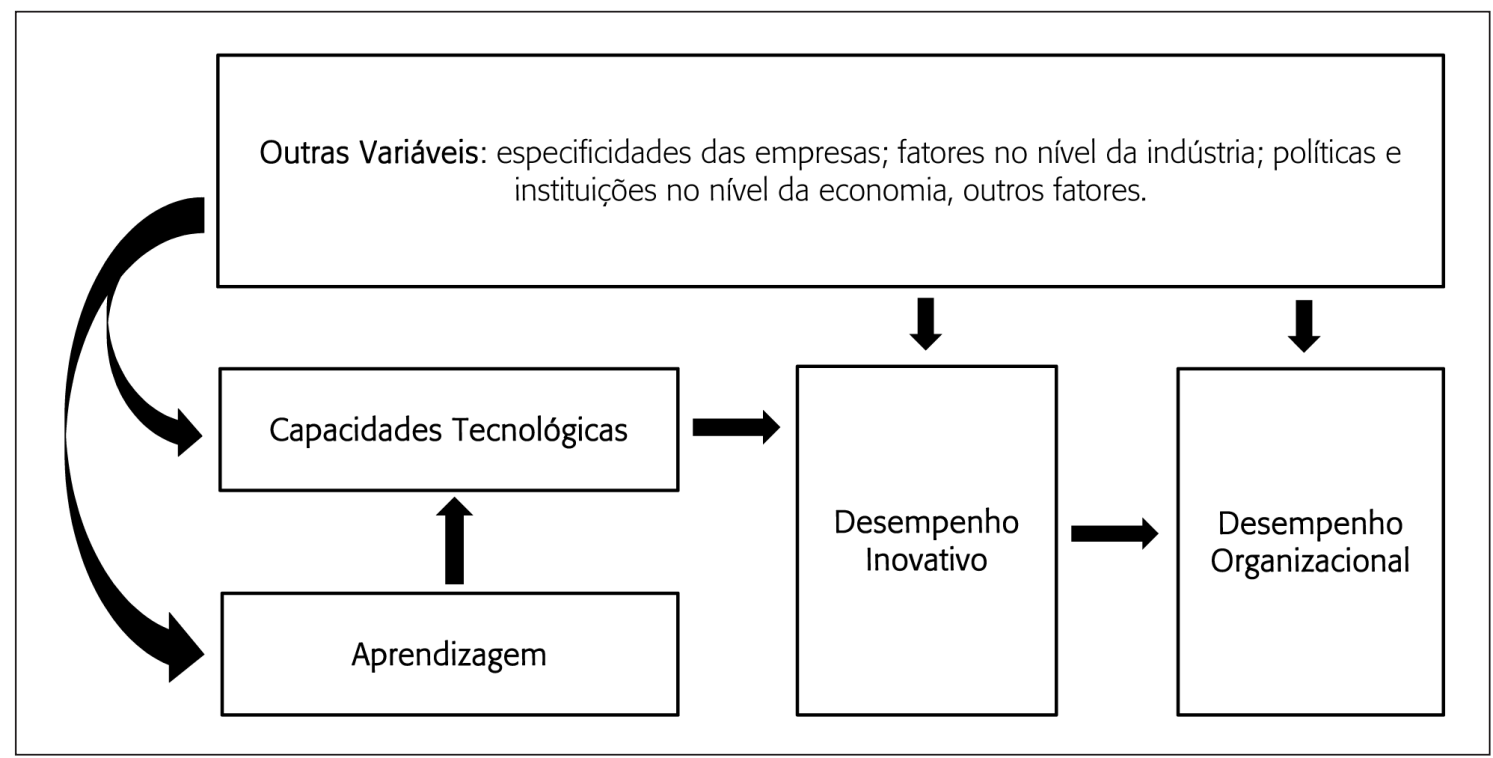

Fonte: Adaptada de Bell e Figueiredo (2012).

Embora este trabalho tenha se utilizado da linha teórica genérica descrita, optou-se pelo foco na relação coevolucionária entre políticas públicas/instituições e capacidades tec- 
nológicas, pois, como posto por Avnimelech e Teubal (2008) e Saviotti e Pyka (2004), as mudanças qualitativas na economia são fruto do processo evolucionário no nível micro entre empresas e instituições ou nas trajetórias das políticas públicas e instituições. Para os autores, tais mudanças se dariam pela coevolução entre o setor de negócios e os alvos das políticas governamentais, principalmente no caso das indústrias infantes, como é o caso do setor em estudo, a indústria de biodiesel no Brasil.

Alguns autores utilizam o termo coevolução para relacionar o processo compartilhado, e por vezes simbiótico, de evolução do ambiente e das suas políticas/instituições com as empresas e seus setores (e.g.: Dieleman e Sachs, 2008; Jacobides e Winter, 2005; Levinthal e Myatt, 1994; Lewin, Long e Carroll, 1999; Mckelvey, 1997; Nelson, 1995). De fato, Nelson e Winter (1982) já discorriam em seus estudos que a estrutura industrial e o avanço tecnológico interagiam de modo complexo, porém foi a partir dos trabalhos pioneiros de Lewin, Long e Carroll (1999), complementados por Dijksterhuis, Van Den Bosch e Volberda (1999), que se construiu um framework conceitual descritivo, contendo, essencialmente, três tipos de evolução: macro (ao nível da indústria), micro (ao nível da firma) e coevolução, que introduz o papel do ambiente e das instituições em mútua evolução com os níveis da indústria e da firma.

É possível identificar na literatura diversas contribuições em linha com a relação de coevolução aqui proposta. Lewin e Volberda (1999), por exemplo, apresentaram importante framework cujos resultados demostraram que as organizações são nada mais que uma junção do esforço de gestão e das pressões impostas pelo ambiente. Complementarmente, Yang (2011) identificou diversas propriedades dos processos de coevolução, tais como: i) multidimensionalidade/envolvimento, ii) condição inicial e consequências, iii) feedback positivo e bicausalidade, iv) causalidade em multidireções, e v) não linearidade. Não obstante, enquanto alguns estudos (e.g.: Carney e Gedajlovic, 2002; Suhomlinova, 2006) destacaram a importância das conexões entre o ambiente e seus diferentes atores, outros (e.g.: Rim, Choung e Hwang, 1998) enfatizaram que as ações públicas e privadas são necessárias para construir vantagens competitivas.

No contexto brasileiro, autores como Dantas e Bell (2011) estudaram o processo coevolucionário das capacidades tecnológicas de uma grande companhia de petróleo brasileira por meio de suas estratégias e resultados na formação de redes de aprendizado e conhecimento. Rodrigues e Child (2003) também analisaram o processo de coevolução das capacidades tecnológicas, porém utilizando-se do caso de uma grande empresa brasileira do setor de telecomunicações. Esses autores construíram sua análise a partir da perspectiva da coevolução de empresas em ambientes altamente institucionalizados, como é o caso do setor nascente do biodiesel no Brasil.

Percebe-se que o conceito de coevolução parte do princípio de que as variáveis ambientais estabelecem uma relação de mútua influência com a evolução tecnológica das empresas e que os diversos estudos relacionando à temática ressaltam, normalmente, as políticas industriais e de inovação e seus sistemas regionais, nacionais e setoriais de inovação, incluindo neles a diversidade de instituições de suporte às firmas que coexistem nesses ambientes, tais como universidades, institutos de pesquisa e associações empresariais. Contudo, ainda exis- 
te certa carência de trabalhos empíricos sobre coevolução aplicados à realidade dos países em desenvolvimento e que considerem a peculiaridade das chamadas latecomer firms, em especial na contribuição de frameworks que melhor expliquem essas relações. Desse modo, o framework proposto no estudo (figura 2) considerou que a coevolução se daria entre os níveis macro/meso (i.e.: políticas/instituições) e o nível micro (i.e.: capacidades tecnológicas), considerando a evolução das capacidades tecnológicas influenciadas, de forma coevolutiva, pelas políticas/instituições voltadas para o setor.

Figura 2

Framework analítico proposto

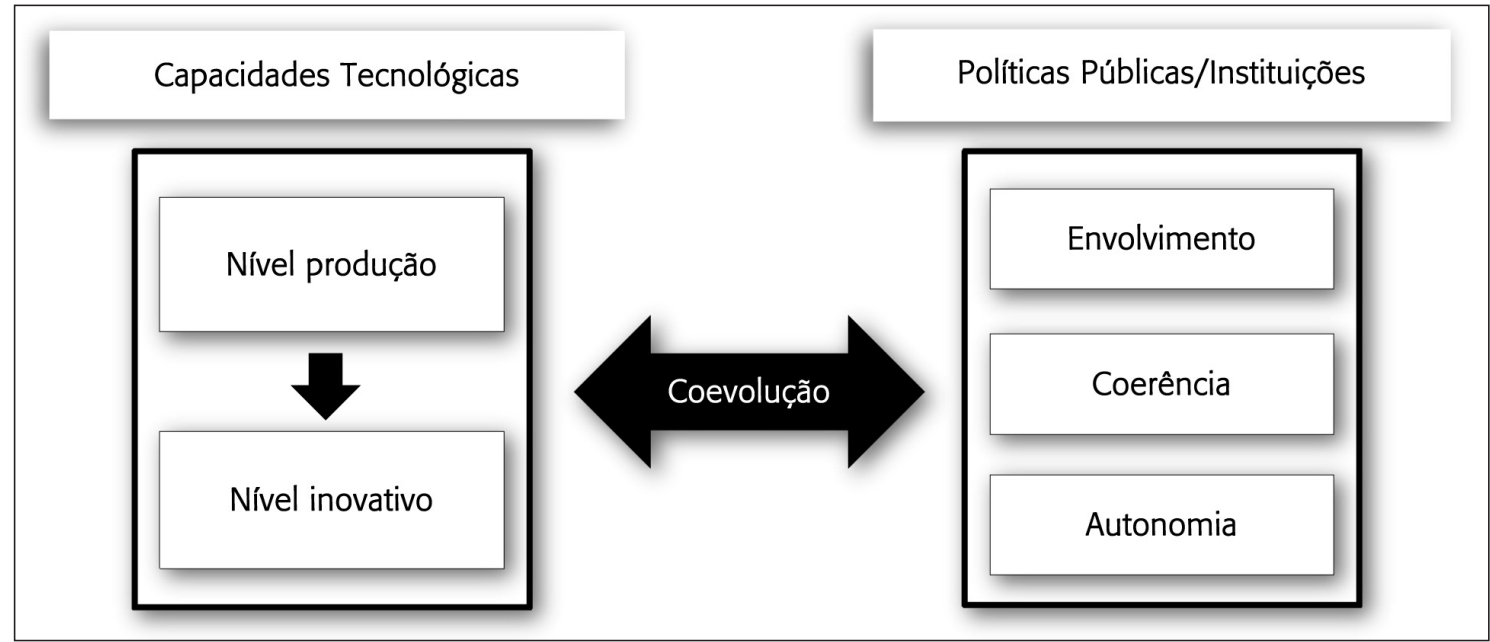

Fonte: Elaboração própria.

Os construtos do framework analítico são considerados (figura 2), para efeitos de análise, da seguinte forma: i) capacidades tecnológicas, aqui abordado sob a ótica de acumulação das latecomer firms de economias em desenvolvimento e sua dinâmica de evolução (e.g.: Bell e Figueiredo, 2012) e ii) políticas/instituições, abordado sob a perspectiva de interação contínua e influência mútua ao longo do tempo (e.g.: Avnimelech e Teubal, 2008), segundo as dimensões envolvimento, coerência e autonomia (e.g.: Evans, 1995). A descrição teórica dos construtos empreendida a seguir tem o intuito de clarificar e apresentar o ferramental específico acerca da operacionalização do estudo proposto.

\subsection{Capacidades tecnológicas}

Este trabalho se apropria dos ensinamentos de Bell e Pavitt (1993, 1995), Lall (1992) e Dutrénit (2000), os quais definem capacidades tecnológicas como os recursos necessários para 
gerar e gerenciar a mudança técnica, as habilidades, os conhecimentos, as experiências e a estrutura institucional da organização, podendo ainda ser divididas em duas dimensões distintas: i) capacidades de produção, relacionadas ao aumento de produtividade e utilização de técnicas mais avançadas de produção; e ii) capacidades inovativas, relacionadas à geração de novos produtos, processos, tecnologias, conhecimentos, entre outros.

Ambas as formas, como observado em Bell e Figueiredo (2012) e Dutrénit (2000), incluem a capacidade de formular e implementar diferentes estratégias de dimensão organizacional, que vão desde a busca pela diferenciação/especialização até a orquestração de players no desenvolvimento de pesquisas de ponta. Alguns autores, contudo (e.g.: Hobday, Rush e Bessant, 2004; Figueiredo, 2009; Ariffin e Figueiredo, 2004; Ariffin, 2010), dividem as capacidades tecnológicas em quatro, seis e até sete subníveis, permitindo um maior detalhamento na descrição da evolução tecnológica das firmas.

Entende-se que as empresas latecomer iniciam sua trajetória de acumulação de capacidades tecnológicas em níveis de produção e evoluem para níveis mais avançados (i.e.: inovadores) (Kim, 1997). Essa evolução exige, principalmente, esforços em aprendizagem tecnológica para que a empresa possa alcançar as líderes do mercado. Entretanto, essa fronteira tecnológica está sempre em movimento, exigindo da empresa que almeja figurar entre os principais players do mercado uma aceleração na velocidade de acumulação de capacidades tecnológicas se pretende alcançar e manter-se entre as líderes do setor.

\subsection{Políticas públicas/instituições industriais e de fomento ao desenvolvimento tecnológico}

Outro construto analisado no framework analítico é o ambiente, notadamente as políticas/ instituições industriais voltadas ao fomento do desenvolvimento tecnológico e da inovação. O estudo desta variável é corroborado por Cimoli, Dosi e Stiglitz (2008), os quais aduzem que as políticas e instituições, de fato, afetam as capacidades tecnológicas das organizações, bem como a forma como elas aprendem. No caso restrito ao estudo, o das indústrias nascentes, Avnimelech e Teubal (2008) fornecem importante contribuição, identificando e classificando os programas dessas políticas em duas vertentes: i) horizontal: que suportam programas de P\&D/inovação sem especificar um setor, tecnologia ou classe de produtos; e ii) targeted: focados em um setor ou tecnologia cujo principal objetivo é a criação de novas estruturas de multiagentes.

Entretanto, Rodrik (1995) argumenta que, em economias emergentes, dificilmente as regras para a implantação dessas políticas são seguidas e que o sucesso do projeto pode ser explicado a partir de dois princípios, o da autonomia do Estado e o da coerência das políticas. Com efeito, o conjunto de autonomia e coerência é a base para que as firmas se envolvam com essas políticas, o que, de acordo com Evans (1995), ocorre na presença de um conjunto concreto de conexões que unam o Estado, íntima e "agressivamente", a grupos 
sociais com quem o mesmo possua projetos em comum (i.e.: envolvimento). Para o autor, a autonomia associada ao envolvimento é força fundamental na eficácia das políticas públicas. A parceria fornece fontes de inteligência e canais de implementação que acentuam a competência do Estado. A autonomia complementa a parceria, protegendo o Estado da captura que iria destruir a coesão do Estado em si e, eventualmente, minar a coerência de seus interlocutores sociais.

\section{Desenho da pesquisa}

O presente artigo apresenta os resultados de um estudo do tipo exploratório e de caráter qualitativo com aplicação em campo empírico sobre o caso da Petrobras Biocombustível (PBio), especificamente na divisão de produção de biodiesel no Brasil. A escolha do caso se deveu às características de forte relação da trajetória tecnológica da PBio e das políticas públicas direcionadas à indústria de biodiesel no Brasil, uma vez que a empresa é uma subsidiária integral da Petrobras, empresa de economia mista com forte participação do governo e com presença significativa no mercado mundial de petróleo e gás. Tais características reúnem um caso de interesse para as pesquisas que avancem no entendimento dos processos de coevolução tecnológica, principalmente em países em desenvolvimento, tendo sido desenvolvida a partir de duas fases de campo, conforme exposto na tabela 1.

Na primeira fase foi realizada uma investigação sobre as capacidades tecnológicas de produção de biodiesel e os diferentes níveis de sua evolução. Nessa etapa foram realizadas 13 entrevistas formais, quatro visitas técnicas a usinas, institutos e laboratórios de pesquisa e ao escritório central da Agência Nacional de Petróleo (ANP), além de vasta coleta de informações em literatura técnica especializada, websites com informações técnicas e materiais de divulgação da empresa investigada. Na segunda fase foi empreendida uma estratégia de triangulação, considerando os pontos em comum existentes entre as diferentes falas, observações colhidas nas instalações visitadas e nos diversos documentos analisados. Nesse particular, a evidência referente a uma das dimensões que apresentasse coerência lógica e temporal, bem como recorrência em fontes diferentes, seria considerada empiricamente relevante e incorporada aos dados para análise.

Foi realizada ainda a checagem das evidências empíricas da evolução tecnológica das usinas da PBio por meio de 20 entrevistas formais e oito visitas técnicas às usinas da PBio (Candeias (BA), Quixadá (CE)), onde foram entrevistados profissionais de diferentes níveis da empresa (diretores, gerentes de tecnologia, pesquisadores, engenheiros de processo e supervisores). As entrevistas, nas duas fases da pesquisa, tiveram duração média de duas horas e 30 minutos e, embora não tenham sido efetuados registros em áudio, com o intuito de evitar a inibição dos entrevistados, foram geradas notas das entrevistas e checagem posterior de informações prestadas por e-mail e/ou telefone. 
Tabela 1

Principais fontes empíricas das informações

\begin{tabular}{|c|c|c|}
\hline Fontes & Entrevistas & Visitas Técnicas \\
\hline Primeira fase (institutos, universidades e laboratórios, ANP) & & 4 \\
\hline Pesquisadores & 8 & \\
\hline Especialistas (consultores) & 2 & \\
\hline Gestores da PBio & 3 & \\
\hline Total da primeira fase $(A)$ & 13 & 4 \\
\hline \multicolumn{3}{|l|}{ Segunda Fase } \\
\hline Sede PBio/Cenpes (Rio de Janeiro - RJ) & & 1 \\
\hline Diretores/Gerentes & 6 & \\
\hline Pesquisador & 2 & \\
\hline Planta-Piloto (Guamaré - RN) & & 1 \\
\hline Gerentes/Engenheiros/Pesquisadores & 1 & \\
\hline \multicolumn{3}{|l|}{ Supervisores } \\
\hline Usinas (Candeias - BA, Quixadá - CE) & & 6 \\
\hline Gerentes/Engenheiros & 7 & \\
\hline Supervisores/Técnicos & 4 & \\
\hline Total da segunda fase (B) & 20 & 8 \\
\hline TOTAL DA PESQUISA (A+B) & 33 & 12 \\
\hline
\end{tabular}

Fonte: Elaboração própria.

As informações foram tratadas utilizando protocolos de coleta e de redução e sintetização em direção à validação do framework proposto por meio da identificação de evidências empíricas que permitissem sua checagem, como descrito em Miles e Huberman (1984). Foi realizada a identificação da trajetória de coevolução das capacidades tecnológicas da PBio em conjunto com a evolução das políticas públicas e instituições direcionadas ao estímulo do desenvolvimento da indústria do biodiesel no Brasil, considerando um período de nove anos que abrangeu desde a concepção tecnológica na Petrobras, incluindo a criação da planta piloto, até a implantação e o funcionamento das usinas da PBio.

O estudo se concentrou na evolução das três principais usinas; contudo, considerou a futura implantação da usina do Pará como resultado do processo de coevolução das três usinas principais (3UPs). A análise evolucionária das 3UPs se deu considerando três funções: i) matérias-primas; ii) investimentos; e iii) processos e organização da produção. Relacionada a essas funções, o presente estudo analisou a evolução das tecnologias de produção agrícola 
incentivadas pela PBio/Petrobras e associadas à agricultura familiar, importante aspecto e alvo do Programa Nacional de Produção e Uso de Biodiesel (PNPB) e área de elevado esforço da empresa estudada.

Consideraram-se para a análise os quatro anos que antecederam a implantação das primeiras 3UPs (2004 a 2007) e um segundo período de assimilação e geração acelerada das capacidades tecnológicas, que foi da implantação das 3UPs até um ano antes do início da duplicação da capacidade das usinas (2008 a 2009). O terceiro período considerado para análise se deu a partir de 2010 até 2012, no qual se apresentou maior amadurecimento tecnológico.

\subsection{Operacionalização das variáveis}

As evidências empíricas foram trabalhadas na perspectiva da coevolução, considerando a comparação no tempo entre a evolução das capacidades tecnológicas da PBio e a evolução do comportamento das políticas e instituições voltadas ao estímulo do setor de biodiesel no Brasil. Para os fins do estudo, inferiu-se que PBio e Petrobras não poderiam ser consideradas empresas totalmente separadas, até porque não o são. Assim, a PBio, subsidiária integral, e a Petrobras, analisadas a partir da trajetória das capacidades tecnológicas em produção de biodiesel, já coevoluíam antes mesmo de a PBio ter sido constituída formalmente em 2008. Prova disso foi a inauguração de duas usinas-piloto em 2005.

No caso das capacidades tecnológicas, a evolução foi dividida em quatro funções tecnológicas, a saber: i) matérias-primas: que se relacionam com a decisão dos tipos de materiais a ser utilizados, seu processo de estocagem, preparo, manuseio, seleção, prospecção e teste de novas matérias-primas; ii) equipamentos e investimentos: se refere à capacidade de ajustes, melhorias, modificações, análise de aquisição e otimização do uso de equipamentos e máquinas industriais; iii) produtos e processos: representando as capacidades de ajuste e melhorias no processo de produção, parametrização e melhorias na qualidade do biodiesel e subprodutos; e iv) tecnologia de produção agrícola: que diz respeito às capacidades geradas pelos produtores agrícolas a partir da relação com a PBio.

Às funções especificadas foram estabelecidos níveis de gradação que vão do básico de produção ao mais avançado nível inovativo, tendo sido considerados, ao todo, seis níveis, com o objetivo de descrever melhor as especificidades da trajetória tecnológica das usinas de produção de biodiesel, dos quais: os níveis um e dois caracterizam as capacidades de produção; os níveis três, quatro e cinco caracterizam as capacidades inovativas; e o nível seis, que caracteriza as capacidades acumuladas de líder mundial. Essas quatro funções foram então reunidas em uma função macro, denominada tecnologias industriais. Pôde-se inferir que, quanto maior o nível identificado, maiores as capacidades inovativas das usinas e, consequentemente, da PBio. Os critérios de classificação têm como base a taxonomia dos trabalhos desenvolvidos por Lall (1992) e Bell e Figueiredo (2012).

Por fim, foram analisadas as políticas e instituições considerando sua evolução para níveis das características evolutivas autonomia, coerência e envolvimento (Evans, 1995; Rodrik, 
1995), que se somam. Essa classificação se deu pela coleta de evidências empíricas trianguladas entre entrevistas formais, análise documental e de literatura técnica específica, permitindo a atribuição de valores (de zero a três), na forma de uma escala, que demonstram os níveis evolutivos das políticas/instituições, sendo: zero = não existem evidências que confirmem a característica evolutiva; um = existem poucas evidências que confirmam a característica evolutiva; dois = existe parcialmente; e três = existe plenamente, perfazendo, assim, uma variabilidade de no mínimo zero a no máximo nove (soma das três características evolutivas), para evolução das políticas/instituições.

\subsection{Análise das relações entre capacidades tecnológicas e evolução das políticas}

Para realizar a análise das relações entre capacidades tecnológicas e nível de evolução das políticas utilizou-se um diagrama em um eixo cartesiano que classifica as diferentes relações e possíveis fases que as empresas podem apresentar. Assim, os diagramas são divididos em quadrantes com diferentes combinações entre níveis de capacidade tecnológica (figura 3).

Figura 3

Diagrama de coevolução entre políticas/instituições e capacidades tecnológicas

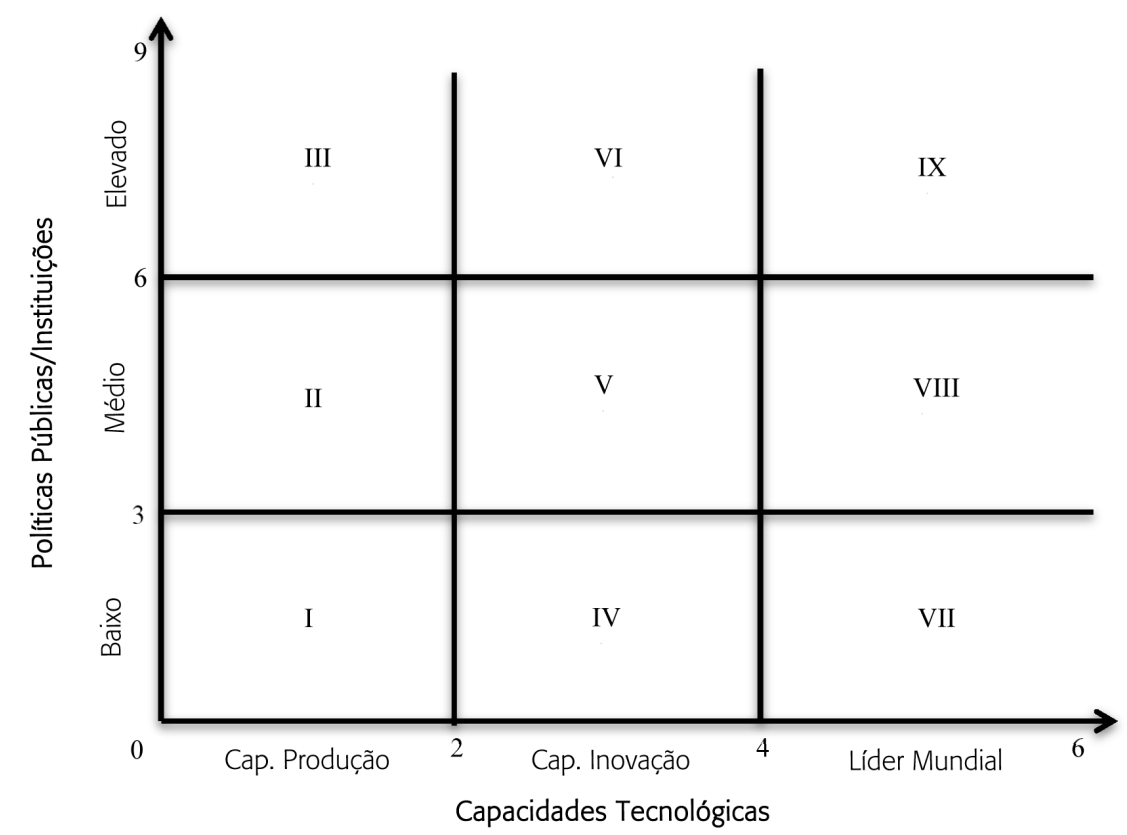

Fonte: Elaboração própria. 
O diagrama apresenta um conjunto de nove quadrantes de coevolução entre políticas/ instituições e capacidades tecnológicas. A situação ideal se configura quando as empresas apresentam sua estrutura evolutiva iniciando a partir do quadrante I (capacidade tecnológica de produção com políticas/instituições de baixo nível de evolução) para níveis de capacidade tecnológica de liderança mundial e políticas/instituições com elevados níveis de evolução. Logo, por meio desse diagrama, será realizada a análise da evolução temporal da coevolução entre políticas/instituições e as capacidades tecnológicas da PBio.

\section{Resultados e discussão}

As experiências na condução de usinas de petróleo e gás, as experimentações na planta-piloto de Guamaré e a pressa imposta pela conjuntura política do setor foram, na opinião de alguns entrevistados, o que levou a Petrobras a comprar a tecnologia industrial das 3UPs da empresa norte-americana Craw, não obstante o fato de que tecnologia semelhante se encontrava em fase de amadurecimento na planta-piloto. Ainda nesse período, a Petrobras deslocou parte de sua competência, operadores, supervisores e engenheiros com o intuito de proporcionar intenso treinamento a essas equipes, dando, assim, início ao funcionamento das 3UPs, como que em um esquema de partida assistida conduzida pelos técnicos da Craw, caracterizando o alcance dos níveis tecnológicos I e II (básico e avançado de produção, respectivamente). Dessa forma, as 3UPs iniciaram o processo produtivo, em 2008, com as capacidades de produção nos níveis básico e avançados praticamente concluídas.

A partir de 2008, a pressão sobre o uso de matérias-primas que fossem oriundas da agricultura familiar fez com que a PBio, em conjunto com a Petrobras/Cenpes, empreendesse forte investimento em pesquisa na área, em convênio com universidades públicas e com a Empresa Brasileira de Pesquisa Agropecuária (Embrapa). Em paralelo, foram realizados trabalhos de conclusão de pendências tecnológicas, advindos da partida assistida das usinas, colocando os operadores, supervisores e engenheiros num processo de mescla de conhecimentos anteriores com os acertos da tecnologia recém-adquirida, o que promoveu intensas melhorias e, segundo alguns entrevistados, surpreendeu os técnicos americanos da Craw, gerando um processo de aceleração das capacidades tecnológicas da PBio entre 2008 e 2009, que a fez alcançar, nas funções matérias-primas, investimentos e processos e organização da produção, o nível básico inovador (Lall, 1992; Bell e Figueiredo, 2012).

O resultado dessa evolução culminou na decisão de duplicar a produção das 3UPs sem, necessariamente, ter de dobrar os investimentos iniciais. Nesse período, as usinas desenvolveram misturas de matérias-primas mais adequadas, ajustando uma tecnologia adaptada ao óleo de soja e a outras matérias-primas, principalmente àquelas ligadas à agricultura familiar e as de menor preço no mercado brasileiro (e.g.: o sebo animal), realizaram melhorias no maquinário, o que encurtou o tempo do processo, e ampliaram a carga das usinas, ainda em 2009. Adicionalmente, a agenda semanal de encontros, presencial ou por videoconferência, tornou possível a disseminação do conhecimento e da evolução tecnológica entre as 3UPs 
quase que uniformemente. A sinergia de conhecimentos gerados foi introduzida na plantapiloto de Guamaré ( $\mathrm{RN}$ ), permitindo que a empresa alcançasse os níveis III e IV, inovador básico e inovador intermediário, respectivamente, resultados em linha com o proposto por Bell e Figueiredo (2012) para o estudo da evolução tecnológica.

A partir de 2010, a PBio passou a modificar os processos e equipamentos das 3UPs, retirando a etapa de pré-filtragem e incorporando o uso de gás nas caldeiras, principalmente na usina de Candeias, na Bahia, dada a abundância pela proximidade da refinaria de petróleo e gás da Petrobras na cidade de Camaçari (BA). Ademais, a incorporação de testes de blended, a consolidação da participação de laboratórios químicos no ajuste de parâmetros da borra com o ponto de fulgor do biodiesel, sua preparação para certificação ISO 17.025, bem como a possibilidade da entrada, de forma misturada, de óleos que sofriam pré-tratamento separados foram responsáveis por estabelecer a PBio no nível V (inovador avançado). Esse resultado, mais uma vez, corrobora a proposição de Bell e Figueiredo (2012), demonstrando que firmas de países em desenvolvimento também são capazes de acumular e ascender a níveis inovadores de capacidades tecnológicas.

Considerando a evolução tecnológica da função não industrial (i.e.: tecnologias de produção agrícola), os níveis tecnológicos alcançados foram menores que as funções industriais das 3UPs, o que é compreensível uma vez que essa área não é parte do core business, nem da Petrobras e nem da PBio. Assim, até o segundo período analisado, a PBio só havia alcançado o nível básico e avançado de produção, apesar dos esforços de um conjunto de universidades associadas à PBio/Petrobras e à Embrapa. Esse desempenho inferior pode também ser creditado ao processo mais lento de maturação no desenvolvimento de tecnologias agrícolas, decorrente da natureza dessas pesquisas, resultado até certo ponto esperado, pois, como mostrado por Figueiredo (2010), que analisou o setor de papel e celulose, a evolução dos níveis de capacidades tecnológicas ligadas ao setor agrícola é, de fato, mais lenta, exigindo um período de maturação mais longo.

\section{1 Políticas públicas}

O estabelecimento do grupo de trabalho interministerial, em julho de 2003, com o objetivo de apresentar estudos sobre a viabilidade de utilização do biodiesel como fonte alternativa de energia, culminou com a criação do PNPB ao final de 2004 e, em janeiro de 2005, por meio da Lei no 11.097, o biodiesel pôde, finalmente, ser introduzido na matriz energética brasileira. A referida lei estabeleceu uma mistura obrigatória do biodiesel com o diesel mineral que inicialmente seria de 2\%, em 2005, até 5\%, em 2013. Também em 2005 foi promovida uma série de reduções tributárias para as usinas que incentivassem a inserção da agricultura familiar na cadeia produtiva do biodiesel (i.e.: por meio do selo social), iniciativa esta apoiada por outro instrumento de política do governo federal, o Plano Nacional de Agroenergia (PNA). O PNPB contaria ainda com dois programas de financiamento, o Programa de Apoio Financeiro a In- 
vestimentos do Biodiesel e o Programa Nacional de Fortalecimento da Agricultura Familiar (Pronaf), ambos financiados por bancos estatais.

Com relação à eficácia do selo social, o que se percebeu foi que inúmeras indústrias apenas compravam da agricultura familiar, mas não usavam as matérias-primas na produção do biodiesel, principalmente os óleos de mamona e de dendê. Não obstante, embora o número de aquisições da agricultura familiar tenha aumentado ao longo dos anos, a maior parte dessas compras se originava de produtores de soja de fora da região semiárida. Além disso, os financiamentos para o setor, que são subsidiados, possuem trajetórias diferentes daqueles ligados à indústria. De fato, enquanto na indústria os investimentos têm se mostrado como uma importante ferramenta na aquisição e desenvolvimento de capacidades tecnológicas, na agricultura familiar, por meio do Pronaf, não houve o mesmo desempenho, principalmente no caso do plantio da mamona, na região do semiárido nordestino. Esse fato, na opinião de alguns entrevistados, resta na dificuldade de integração produtiva da agricultura familiar de maneira sustentável, parte porque a produção desses agricultores constitui uma pequena parcela do todo de matérias-primas utilizadas pelas usinas, parte porque essa produção, muitas vezes, é comprada e não utilizada na produção do biodiesel, o que desvirtua a lógica do selo e a ideia do impacto da cadeia produtiva do biodiesel na geração da renda da agricultura familiar. Em resumo, e utilizando-se dos ensinamentos de Rodrik (1995) e Evans (1995), o que se percebe é que o envolvimento dos pequenos produtores rurais não vem se dando de forma tão integrada, fazendo com que o incentivo perca parte de sua coerência.

No que diz respeito ao incentivo para a mistura do biodiesel com o diesel mineral, temse que a evolução nos percentuais ao longo dos anos e, principalmente, a obrigatoriedade da mistura, a partir de 2008, contribuíram para que vários dos prazos e percentagens de mistura fossem antecipados, permitindo a criação de uma expectativa de demandas futuras que estimula os investimentos e a busca por ganhos de produtividade no setor.

\subsection{Instituições}

Como se pode perceber na tabela 2, a ANP vem apresentando forte atuação na condução dos leilões ao longo dos anos. A elevação do número de ofertantes tem mostrado o nível de envolvimento do setor em função da atuação da agência; entretanto, o que se observa é que, recorrentemente, os leilões têm deixado ofertas não atendidas. Ciente do problema, a ANP vem desenvolvendo um cronograma de acompanhamento desse processo com o intuito de estimular a desconcentração do mercado. Com efeito, segundo dados do Ipea (2012), a desconcentração vem ocorrendo de forma substancial no grupo das cinco e das 10 maiores empresas do mercado: na primeira categoria passou de 61,2\% (2008) para 47,6\% (2011) de concentração; no segundo grupo passou de 88,8\% (2008) para 74,5\% (2011). Todavia, a ANP não conseguiu evitar a concentração na compra da soja como matéria-prima e seu elevado grau de dependência dessa oleaginosa (80\%) o que, de acordo com o Ipea (2012), não favorece a distribuição regional além de possuir baixa inserção social. 
Tabela 2

Evolução dos leilões de biodiesel conduzidos pela ANP

\begin{tabular}{|ccccccc|}
\hline \multirow{2}{*}{ Descrição } & \multicolumn{7}{c|}{ Períodos } \\
\cline { 2 - 7 } & $2006-07$ & 2008 & 2009 & 2010 & 2011 & $2012(1)$ \\
\hline № de ofertantes & 58 & 141 & 223 & 284 & 167 & 212 \\
Volume arrematado & $855.000,00$ & $766.400,00$ & $1.565 .000,00$ & $2.355 .000,00$ & $1.960 .000,00$ & $2.094 .719,00$ \\
\hline
\end{tabular}

(1) Até setembro de 2012.

Fonte: ANP (2012).

Em relação ao fomento à pesquisa, desde 2004, o Conselho Nacional de Desenvolvimento Científico e Tecnológico (CNPq) vem publicando editais voltados ao financiamento de projetos de pesquisa sobre o biodiesel, com valores girando entre 2 milhões até 30 milhões de reais, em 2010 (Martins, 2010). Ao longo desse período, mais de 200 projetos de pesquisas foram contemplados. Esse esforço tem criado uma cultura e uma massa crítica de conhecimento sobre tecnologias voltadas para a produção do biodiesel que, além de fortalecer a Rede Brasileira de Tecnologia em Biodiesel (RBTB), contribui para o estabelecimento de elevados níveis de cooperação entre a PBio, universidades e institutos de pesquisa.

Outra importante instituição é o Cenpes, centro de P\&D da Petrobras, que realiza investigações, testes e experimentos em relação à produção do biodiesel. Em inúmeras entrevistas, o papel do Cenpes foi destacado, principalmente em relação às prospecções iniciais e à validação das melhorias dos processos das usinas da PBio e sua aplicação, como demonstrado na figura 4.

Figura 4

Cenpes e evolução da tecnologia industrial própria da PBio

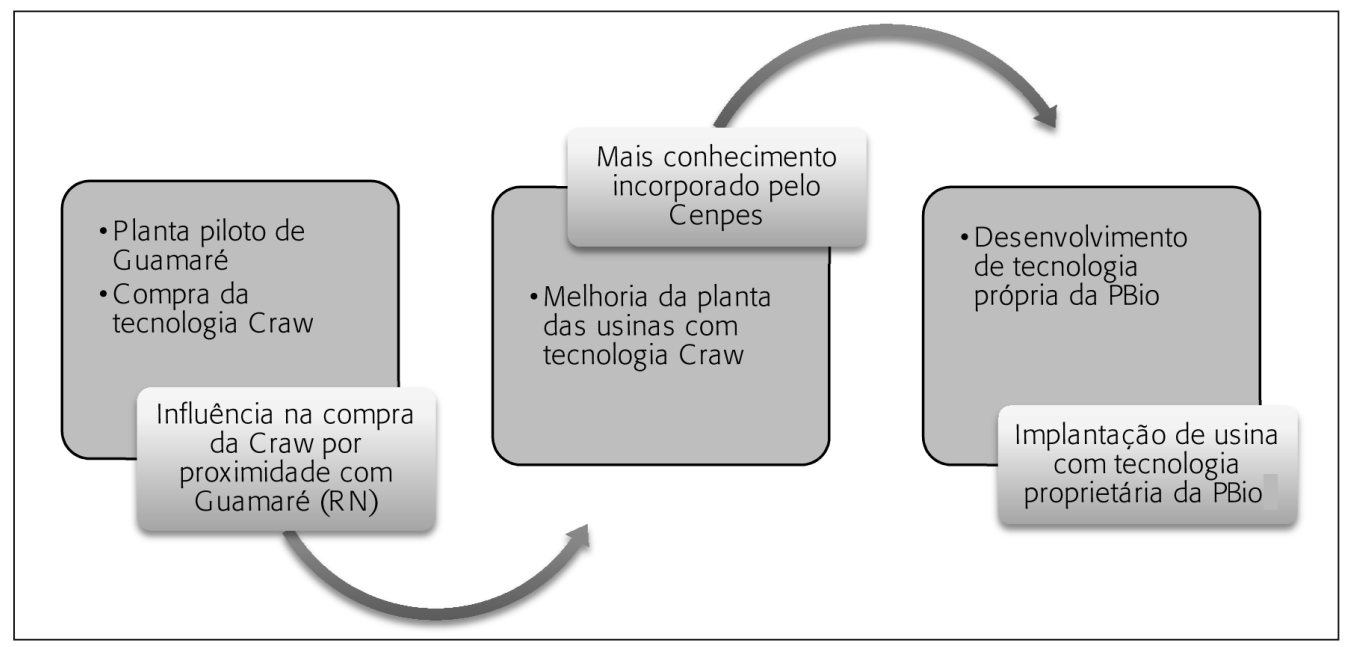

Fonte: Elaboração própria. 
Adicionalmente, o Cenpes iniciou um programa de 300 milhões de reais em P\&D para biocombustíveis, o que, de acordo com exposto em Evans (1995), evidencia o envolvimento com o projeto de evolução tecnológica da PBio. O Cenpes também se revelou um importante instrumento na associação entre a PBio e a empresa portuguesa Galp, para produção, na Europa, do chamado green diesel (diesel mineral que sai da refinaria já misturado ao biodiesel).

Já as redes foram criadas a partir de projetos de interesse da PBio e, portanto, possuíam autonomia limitada do ponto de vista de seus participantes, o que também se verificou de acordo com os preceitos de Rodrik (1995). Contudo, pela vasta quantidade de importantes instituições de pesquisa no segmento agrícola, percebe-se que essas redes vêm apresentando um crescente envolvimento, evidenciado pelas reuniões promovidas de forma regional e nacional (2011 e 2012). Assim, entre os participantes a tendência é de que esse nível de envolvimento, tal como levantado por Evans (1995), aumente ainda mais, haja vista a intencionalidade e a cultura da Petrobras/Cenpes em buscar soluções pela via da pesquisa conjunta com seus parceiros. A evolução das políticas/instituições envolvidas com o setor do biodiesel no Brasil pode ser observada no quadro 1. Nesse caso, foram atribuídas notas para os níveis das políticas/instituições, sendo: (1) baixo, (2) parcial e (3) pleno. Em cada período, as políticas/ instituições podem ir do nível zero (0) a, no máximo, nível nove (9).

\section{Evolução das políticas/instituições de estímulo ao desenvolvimento do setor do biodiesel} no Brasil

\begin{tabular}{|c|c|c|c|c|c|}
\hline & \multirow{2}{*}{ Categorias } & & \multicolumn{3}{|c|}{ Períodos de evolução } \\
\hline & & & 2004-07 & 2008-09 & $2010-12$ \\
\hline \multirow{5}{*}{$\begin{array}{l}\text { Políticas } \\
\text { (PNPB) }\end{array}$} & Prioridades & Selo social & $\begin{array}{c}\text { Autonomia (3) } \\
\text { Coerência parcial (2) }\end{array}$ & $\begin{array}{c}\text { Autonomia (3) } \\
\text { Coerência parcial (2) } \\
\text { Baixo envolvimento (1) }\end{array}$ & $\begin{array}{c}\text { Autonomia (3) } \\
\text { Coerência parcial (2) } \\
\text { Baixo envolvimento (1) }\end{array}$ \\
\hline & \multirow{4}{*}{ Incentivos } & $\begin{array}{l}\text { Financiamen- } \\
\text { tos industriais }\end{array}$ & $\begin{array}{l}\text { Autonomia (3) } \\
\text { Coerência (3) }\end{array}$ & $\begin{array}{c}\text { Autonomia (3) } \\
\text { Coerência (3) } \\
\text { Envolvimento (3) }\end{array}$ & $\begin{array}{c}\text { Autonomia (3) } \\
\text { Coerência (3) } \\
\text { Envolvimento (3) }\end{array}$ \\
\hline & & $\begin{array}{l}\text { Financiamen- } \\
\text { tos agric. } \\
\text { familiar }\end{array}$ & $\begin{array}{c}\text { Autonomia (3) } \\
\text { Coerência parcial (2) }\end{array}$ & $\begin{array}{c}\text { Autonomia (3) } \\
\text { Coerência parcial (2) } \\
\text { Envolvimento parcial (2) }\end{array}$ & $\begin{array}{c}\text { Autonomia (3) } \\
\text { Coerência parcial (2) } \\
\text { Envolvimento parcial (2) }\end{array}$ \\
\hline & & $\begin{array}{l}\text { Redução } \\
\text { tributária }\end{array}$ & Autonomia (3) & $\begin{array}{c}\text { Autonomia (3) } \\
\text { Coerência parcial (2) } \\
\text { Envolvimento parcial (2) }\end{array}$ & $\begin{array}{c}\text { Autonomia (3) } \\
\text { Coerência parcial (2) } \\
\text { Envolvimento parcial (2) }\end{array}$ \\
\hline & & $\begin{array}{l}\text { Mistura com } \\
\text { diesel mineral }\end{array}$ & $\begin{array}{c}\text { Autonomia (3) } \\
\text { Coerência parcial (2) } \\
\text { Envolvimento parcial (2) }\end{array}$ & $\begin{array}{c}\text { Autonomia (3) } \\
\text { Coerência (3) } \\
\text { Envolvimento (3) }\end{array}$ & $\begin{array}{c}\text { Autonomia (3) } \\
\text { Coerência (3) } \\
\text { Envolvimento (3) }\end{array}$ \\
\hline
\end{tabular}




\begin{tabular}{|c|c|c|c|c|}
\hline & \multirow{2}{*}{ Categorias } & \multicolumn{3}{|c|}{ Períodos de evolução } \\
\hline & & 2004-07 & 2008-09 & $2010-12$ \\
\hline \multirow{4}{*}{ Instituiç̧ões } & ANP (Regulação) & $\begin{array}{c}\text { Autonomia (3) } \\
\text { Coerência parcial (2) }\end{array}$ & $\begin{array}{c}\text { Autonomia (3) } \\
\text { Coerência parcial (2) } \\
\text { Envolvimento parcial (2) }\end{array}$ & $\begin{array}{c}\text { Autonomia (3) } \\
\text { Coerência parcial (2) } \\
\text { Envolvimento parcial (2) }\end{array}$ \\
\hline & CNPq (Pesquisas) & $\begin{array}{c}\text { Autonomia (3) } \\
\text { Coerência parcial (2) } \\
\text { Envolvimento parcial (2) }\end{array}$ & $\begin{array}{c}\text { Autonomia (3) } \\
\text { Coerência (3) } \\
\text { Envolvimento (3) }\end{array}$ & $\begin{array}{c}\text { Autonomia (3) } \\
\text { Coerência (3) } \\
\text { Envolvimento (3) }\end{array}$ \\
\hline & Cenpes (P\&D Industrial) & Autonomia (3) & $\begin{array}{l}\text { Autonomia (3) } \\
\text { Coerência (3) } \\
\text { Envolvimento (3) }\end{array}$ & $\begin{array}{l}\text { Autonomia (3) } \\
\text { Coerência (3) } \\
\text { Envolvimento (3) }\end{array}$ \\
\hline & $\begin{array}{l}\text { Redes de pesquisa } \\
\text { (P\&D Agrícola) }\end{array}$ & (0) & $\begin{array}{c}\text { Autonomia parcial (2) } \\
\text { Coerência (3) } \\
\text { Envolvimento parcial (2) }\end{array}$ & $\begin{array}{c}\text { Autonomia parcial (2) } \\
\text { Coerência (3) } \\
\text { Envolvimento parcial (2) }\end{array}$ \\
\hline
\end{tabular}

Fonte: Elaboração própria.

Comparando as políticas com as instituições (tabelas 3 e 4), na média, as últimas alcançaram níveis de evolução maiores com mais autonomia, coerência e envolvimento (Rodrik, 1995; Evans, 1995). Contudo, do ponto de vista da análise individual, as políticas que alcançaram níveis mais altos foram o financiamento industrial e mistura do diesel e, no caso das instituições, as que melhor se saíram foram o CNPq e o Cenpes (tecnologia industrial).

$$
\text { Tabela } 3
$$

Evolução das políticas do biodiesel (níveis/período)

\begin{tabular}{|c|c|c|c|c|}
\hline & \multirow{2}{*}{ Categorias } & \multicolumn{3}{|c|}{ Períodos evolucionários } \\
\hline & & 2004-07 & 2008-09 & $2010-12$ \\
\hline \multirow[t]{3}{*}{ Prioridades } & Selo social (a) & 5 & 6 & 6 \\
\hline & Financiamento industrial & 6 & 9 & 9 \\
\hline & Financiamento agric. familiar & 5 & 7 & 7 \\
\hline \multirow[t]{4}{*}{ Incentivos } & Redução tributária & 3 & 7 & 7 \\
\hline & Mistura com diesel mineral & 7 & 9 & 9 \\
\hline & Média dos incentivos (b) & 5,2 & 7,6 & 7,6 \\
\hline & Média das políticas $(a+b) / 2$ & 5,1 & 6,8 & 6,8 \\
\hline
\end{tabular}

Fonte: Elaboração própria. 
Tabela 4

Evolução das instituições do biodiesel (níveis/períodos)

\begin{tabular}{|cccc|}
\hline \multirow{2}{*}{ Categorias } & \multicolumn{3}{c|}{ Períodos evolucionários } \\
\cline { 2 - 4 } & $2004-07$ & $2008-09$ & $2010-12$ \\
\hline ANP (regulação) & 5 & 7 & 7 \\
CNPq (pesquisa) & 7 & 9 & 9 \\
Cenpes (pesquisa industrial) & 3 & 7 & 7 \\
Redes de Pesquisa (P\&D agrícola) & 0 & 8 & 8 \\
Média das instituiç̃ões & 3,5 & & \\
\hline
\end{tabular}

Fonte: Elaboração própria.

Do exposto, percebe-se ainda que a tecnologia de produção agrícola teve um baixo desempenho em capacidades tecnológicas, problema este em parte explicado pelo tempo de maturação desse tipo de pesquisa que, normalmente, é maior que a industrial, visto que aquela depende de condições naturais, difíceis de serem controladas. Além disso, essa função contou ainda com políticas de selo social e financiamento à agricultura familiar (tabela 3) que não evoluíram a contento ao longo do período estudado. No que concerne às instituições, a ANP e as redes de pesquisa (tabela 4), embora não tenham atingido a pontuação máxima, a exemplo do CNPq e do Cenpes, foram as que mais avançaram no período em estudo.

\subsection{Coevolução}

A partir da análise das informações prestadas pelos entrevistados é possível inferir certa relação evolucionária entre as capacidades tecnológicas da PBio e das políticas públicas/instituições. De fato, a percepção que se tem é a de que as políticas que mais evoluíram no período em estudo (i.e.: financiamento industrial e mistura com diesel mineral) tenham apresentado maior impacto nas funções tecnológicas industriais e, em um curto período, tenham possibilitado à PBio, em uma indústria nascente, alcançar o nível intermediário inovador, mesmo que de forma incompleta. Todavia, essa performance das funções industriais dificilmente teria ocorrido sem o apoio do CNPq e do Cenpes. Com efeito, o Cenpes acompanhou e fomentou todo o processo de melhorias iniciais das usinas após a partida assistida e, em seguida, todo o desenvolvimento de tecnologia própria da PBio, enquanto o CNPq se apresentava como importante peça no dinamismo da pesquisa, com mais autonomia do que as redes lideradas pelo Cenpes (Rodrik, 1995; Evans, 1995).

Assim, avaliando o nexo causal correspondente à provável relação entre as políticas públicas e as tecnologias industriais (gráfico 1), entende-se que a PBio saiu de uma relação de coerência nas políticas públicas para um nível de envolvimento das políticas com as capacidades inovadoras. Contudo, percebe-se que, mesmo em um nível razoavelmente elevado de envolvimento com as políticas públicas, a PBio não avança para liderança mundial. Nesse caso, 
existem duas possíveis explicações: o Brasil ainda não autoriza a exportação de biodiesel e a decisão da PBio de continuar investindo na evolução do biodiesel de primeira geração. Não obstante, espera-se que dessas decisões surjam rotas alternativas de desenvolvimento que, no futuro, possam beneficiar mais a agricultura, especialmente a de pequeno porte.

\section{Gráfico 1}

\section{Coevolução das políticas públicas e tecnologia industrial}

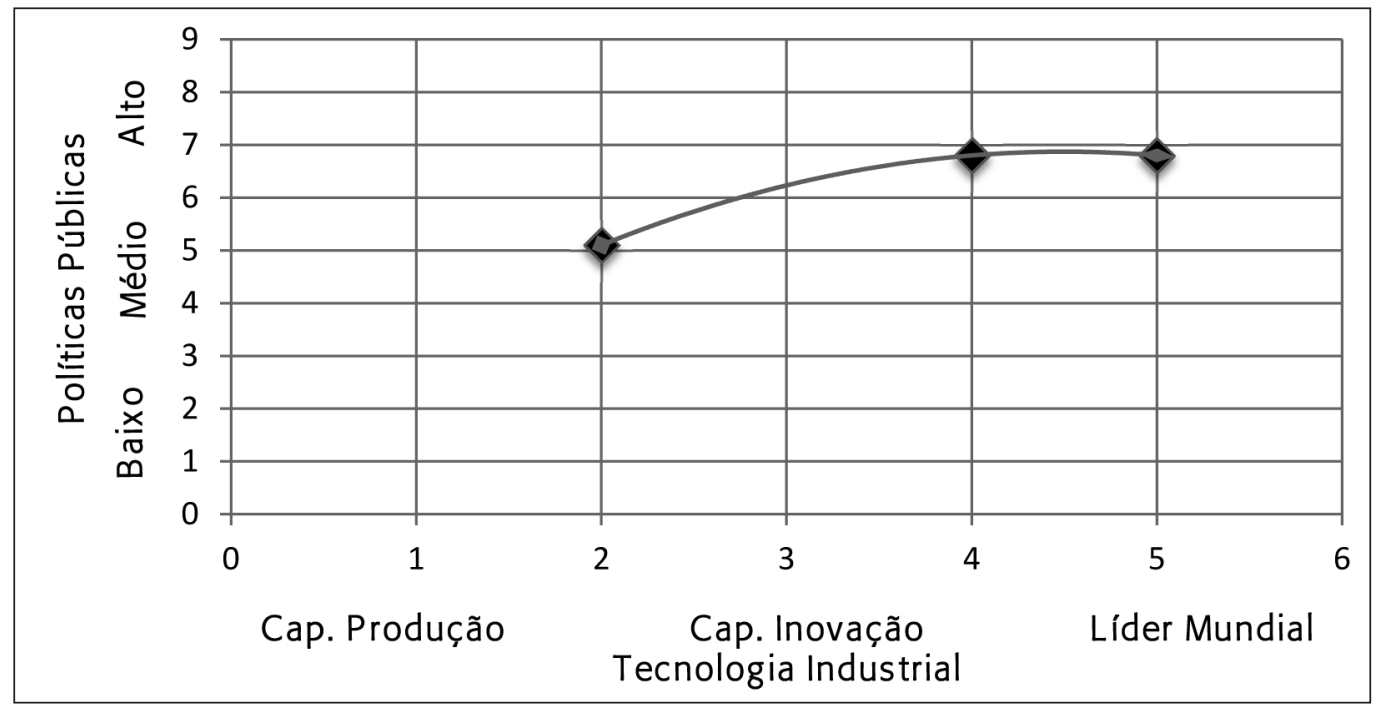

Fonte: Elaboração própria.

No caso da coevolução com as instituições e capacidades tecnológicas (gráfico 2), o comportamento foi semelhante ao observado com as políticas públicas. Todavia, os níveis de envolvimento alcançados foram maiores, o que pode ser explicado pelo envolvimento do Cenpes na melhoria da produção das usinas, no desenvolvimento de tecnologia industrial própria, na descentralização do CNPq em relação ao investimento em pesquisa e em ações da ANP, regulando parte dos investimentos em P\&D. Porém, da mesma forma que na análise anterior, o nível elevado de envolvimento das instituições não foi capaz de elevar a PBio ao patamar de nível tecnológico de liderança mundial.

No caso da coevolução entre capacidades tecnológicas de produção agrícola e políticas públicas, assim como com as instituições (gráficos 3 e 4), a PBio, mesmo com níveis elevados de envolvimento, não evoluiu para o nível de capacidades inovativas. Isso se deveu, provavelmente, a condições ligadas à tradição da produção agrícola brasileira, à resistência sociocultural às mudanças, à dificuldade de transferência de tecnologias associada ao maior tempo necessário para resultados da pesquisa agrícola, dadas suas especificidades naturais, e aos ciclos de vida das culturas. Outro fator limitante, que aparece de forma recorrente na fala dos entrevistados, é a falta de organização e coordenação dos agricultores, elevando a complexidade das operações e da logística de transferência e adoção tecnológica. 
Gráfico 2

Coevolução das instituições e tecnologia industrial

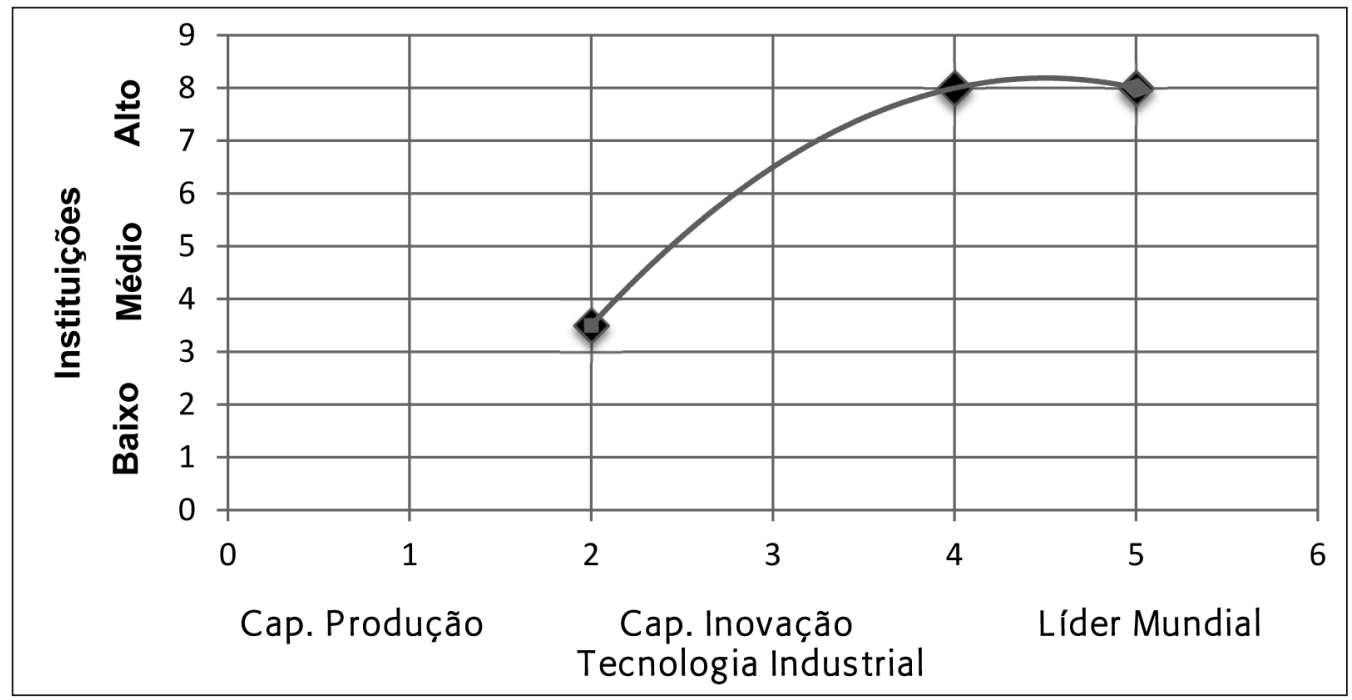

Fonte: Elaboração própria.

Gráfico 3

Coevolução das políticas públicas e tecnologia de produção agrícola

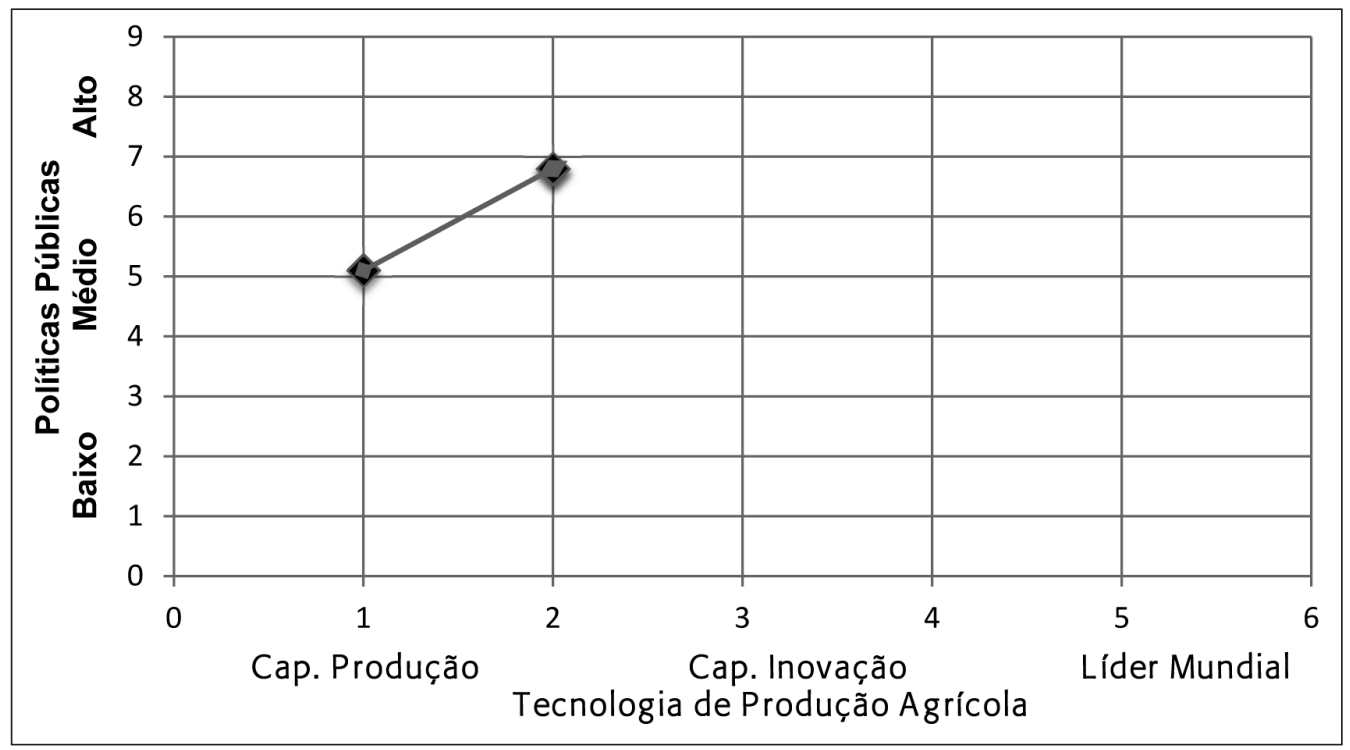

Fonte: Elaboração própria. 
Gráfico 4

Coevolução das instituições e tecnologia de produção agrícola

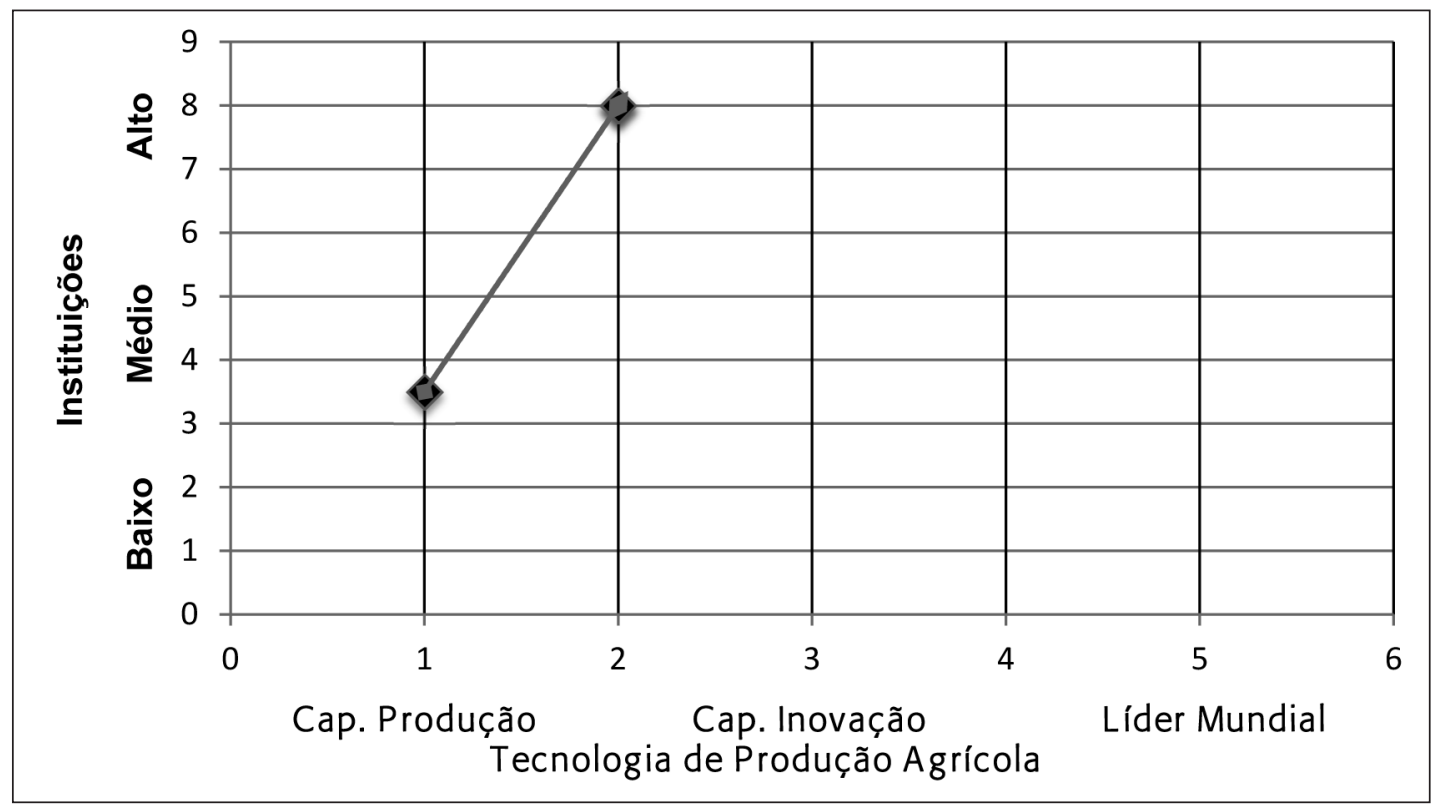

Fonte: Elaboração própria.

\section{Conclusão}

Neste trabalho tentou-se desenvolver uma métrica capaz de capturar a evolução dos níveis de capacidades tecnológicas de usinas produtoras de biodiesel e adequada para avaliar a evolução da PBio, considerando suas tecnologias industriais e a tecnologia de produção agrícola por ela influenciada, bem como pelas instituições e políticas associadas ao setor do biodiesel no Brasil. A análise da métrica demonstrou que a PBio teve evolução acelerada em direção aos níveis inovadores na tecnologia industrial, principalmente se considerarmos o biodiesel de $1^{\text {a }}$ geração, fruto do estoque de capacidades inovadoras de sua controladora, a Petrobras. Entretanto, ao contrário desta, a PBio não pôde ser classificada no nível tecnológico de líder mundial, não só porque faltam realizações na linha de biodiesel de $2^{\text {a }}$ geração, mas também porque a fronteira internacional ainda se encontra muito indefinida.

No âmbito das políticas/instituições, que foram analisadas a partir de uma proposta de categorização, tentou-se mostrar sua evolução temporal por meio de diferentes níveis de atuação junto às empresas-alvo, ajustando a análise a um viés evolucionário que permitisse a avaliação relacional em coevolução com as mudanças tecnológicas do setor. O estudo da coevolução mostrou que os níveis de evolução das políticas/instituições, embora elevados no setor do biodiesel brasileiro, não se apresentaram em níveis tecnológicos de fronteira in- 
ternacional, o que, de certa forma, parece indicar que esse salto se dará por meio de mais esforços internos. Assim, a PBio vive um dilema entre continuar convergindo seus esforços com os interesses de seu principal acionista (i.e.: o governo) e suas políticas/instituições (i.e.: direcionando sua trajetória em função do biodiesel de $1^{\text {a }}$ geração, com maior impacto na agricultura, incluindo a de pequeno porte), ou direcionar esforços em trajetória que conduza ao desenvolvimento de um biodiesel de gerações mais avançadas, como alguns importantes players mundiais estão fazendo.

Outro aspecto relevante se concentra na orientação das políticas públicas/instituições para o setor, que deve ser capaz de incentivar a elevação dos níveis de envolvimento com os demais atores do arranjo, pois, embora o mesmo já se encontre em níveis consideravelmente altos, ainda precisa ser elevado para algumas instituições e políticas, principalmente aquelas que possam direcionar o setor do biodiesel rumo à fronteira tecnológica internacional, fomentando a pesquisa e o desenvolvimento de biocombustíveis mais eficientes, bem como o estímulo à integração da produção de biodiesel à bioeconomia. Entretanto, devem as políticas e instituições ser capazes de proporcionar o crescimento do setor de forma mais autônoma, procurando soluções capazes de, se não eliminar, pelo menos reduzir, gradativamente, a dependência de intervenções do governo e proporcionar a regulação sustentável do mercado como um todo.

Como sugestões de pesquisas futuras é importante que estudos de coevolução de trajetórias tecnológicas com políticas/instituições sejam feitos de forma mais abrangente, considerando mais atores, como outras instituições e empresas relevantes para o setor. Outro aspecto que pode ser estudado é a comparação de processos de coevolução entre diferentes países em desenvolvimento e em outros setores. As sugestões feitas são no sentido de reduzir a principal limitação deste trabalho, que é a impossibilidade de generalização dos resultados, dada a realização do estudo de um único caso.

\section{Referências}

ARIFFIN, Norlela. Internationalization of technological innovative capabilities: levels, types, and speed (learning rates) in the electronics industry in Malaysia. International Journal of Technological Learning, Innovation and Development, v. 3, n. 4, p. 347-391, 2010.

ARIFFIN, Norlela; FIGUEIREDO, Paulo N. Internationalization of innovative capabilities: counter -evidence from the electronics industry in Malaysia and Brazil. Oxford Development Studies, v. 32, n. 4, p. 559-583, 2004.

AVNIMELECH, Gil; TEUBAL, Morris. Evolutionary targeting. Journal Evolutionary Economics, v. 18, n. 2, p. 151-166, 2008.

BARTELS, Frank L. et al. Determinants of national innovation systems: policy implications for developing countries. Innovation: Management, Policy \& Practice, v. 14, n. 1, p. 2-18, 2012. 
BELL, Martin; FIGUEIREDO, Paulo N. Innovation capability building and learning mechanisms in latecomer firms: recent empirical contributions and implications for research. Canadian Journal of Development Studies/Revue Canadienne d'Études du Développement, v. 33, n. 1, p. 14-40, 2012.

BELL, Martin; PAVITT, Keith. Technological accumulation and industrial growth: contrast between developed and developing countries. Industrial and Corporate Change, v. 2, n. 1, p. 157-210, 1993.

BELL, Martin; PAVITT, Keith. The development of technological capabilities. In: HAQUE, Irfan et al. (Coord.). Trade, technology and international competitiveness. Washington: The World Bank, 1995.

BELL, Martin; ROSS-LARSON, Bruce; WESTPHAL, Larry E. Assessing the performance of infant economics. Journal of Development Economics, v. 16, n. 1, p. 101-128, 1984.

CARNEY, Michael; GEDAJLOVIC, Eric. The co-evolution of institutional environments and organizational strategies: the rise of family business groups in the Asean region. Organization Studies, v. 23, n. 1, p. 1-29, 2002.

CIMOLI, Mario; DOSI, Giovanni; STIGLITZ, Joseph E. The future of industrial policies in the new millennium: toward a knowledge-centered development agenda. LEM working paper series, 2008.

CIMOLI, Mario et al. Institutions and policies shaping industrial development: an introductory note. Pisa, Italy: Laboratory of Economics and Management (LEM), Sant'Anna School of Advanced Studies, 2006.

DAHLMAN, Carl J.; WESTPHAL, Larry E. Technological effort in industrial development: An interpretative survey of recent research. In: STEWART, Frances; JAMES, Jeffrey. The economics of new technology in developing countries. Colorado: Westview Press, 1982.

DANTAS, Eva; BELL, Martin. The co-evolution of firm-centered knowledge networks and capabilities in late industrializing countries: The case of Petrobras in the offshore oil innovation system in Brazil. World Development, v. 39, n. 9, p. 1570-1591, 2011.

DERANIYAGALA, Sonali. Analysis of technology and development: a critical review, In: SUNDURAM, Jomo K.; FINE, Ben (Ed.). New development economics: after Washington Consensus. Londres: Tulika; Zed Books, 2006.

DERANIYAGALA, Sonali. The impact of technology accumulation on technical efficiency: an analysis of the Sri Lankan clothing and agricultural machinery industries. Oxford Development Studies, v. 29, n. 1, p. 101-114, 2001.

DIELEMAN, Marleen; SACHS, Wladimir M. Coevolution of institutions and corporations in emerging economies: how the Salim group morphed into an institution of Suharto's crony regime. Journal of Management Studies, v. 45, n. 7, p. 1274-1300, 2008.

DIJKSTERHUIS, Marjolijn S.; VAN DEN BOSCH, Frans A. J.; VOLBERDA, Henk W. Where do new organizational forms come from? Management logics as a source of coevolution. Organization Science, v. 10, n. 5, p. 569-582, 1999.

DOSI, Giovanni; FREEMAN, Christopher; FABIANI, Silvia. The process of economic development: introducing some stylized facts and theories on technologies, firms and institutions. Industrial and Corporate Change, v. 3, n. 1, p. 1-45, 1994. 
DUTRÉNIT, Gabriela. Learning and knowledge management in the firm: from knowledge accumulation to strategic capabilities. Northampton, MA: Edward Elgar Publishing, 2000.

EVANS, Peter B. Embedded autonomy: States and industrial transformation. Princeton, NJ: Princeton University Press, 1995.

FIGUEIREDO, Paulo N. Aprendizagem tecnológica e inovação industrial em economias emergentes: uma breve contribuição para o desenho e implementação de estudos empíricos e estratégias no Brasil. Revista Brasileira de Inovação, v. 3, n. 2, p. 323-361, jul./dez. 2009.

FIGUEIREDO, Paulo N. Discontinuous innovation capability accumulation in latecomer natural resource-processing firms. Technological Forecasting and Social Change, v. 77, n. 7, p. 1090-1108, 2010.

FIGUEIREDO, Paulo N. Industrial policy changes and firm-level technological capability development: evidence from Northern Brazil. World Development, v. 36, n. 1, p. 55-88, 2008.

HOBDAY, Michael; RUSH, Howard; BESSANT, John. Approaching the innovation frontier in Korea: the transition phase to leadership. Research Policy, v. 33, n. 10, p. 1433-1457, 2004.

JACOBIDES, Michael G.; WINTER, Sidney G. The co-evolution of capabilities and transaction costs: explaining the institutional structure of production. Strategic Management Journal, v. 26, n. 5, p. 395-413, maio 2005.

JACOBSSON, Staffan; BERGEK, Anna. A framework for guiding policy-makers intervening in emerging innovation systems in "catching-up" countries. The European Journal of Development Research, v. 18, n. 4, p. 687-707, 2006.

KIM, Linsu. Imitation to innovation. The dynamics of Korea's technological learning. Boston: Havard Business School Press, 1997.

KIM, Linsu. National system of industrial innovation: dynamics of capability building in Korea. In: NELSON, Richard R. (Ed.). National innovation systems: a comparative analysis. Nova York: Oxford University Press, 1993.

KROZER, Yoram; NENTJES, Andries. Environmental policy and innovations. Business Strategy and the Environment, v. 17, n. 4, p. 219-229, 2008.

LALL, Sanjaya. Reinventing industrial strategy: the role of government policy in building industrial competitiveness. Annals of Economics and Finance, v. 14, n. 2, p. 785-829, 2013.

LALL, Sanjaya. Technological capabilities and industrialization. World Development, v. 20, n. 2, p. 165-186, 1992.

LALL, Sanjaya; LATSCH, Wolfram. Import liberalization and industrial performance: the conceptual underpinnings. Development and Change, v. 29, n. 3, p. 437-465, 1998.

LALL, Sanjaya; TEUBAL, Morris. "Market-stimulating” technology policies in developing countries: a framework with examples from East Asia. World Development, v. 26, n. 8, p. 1369-1385, 1998.

LATSCH, Wolfram. The possibility of industrial policy. Oxford Development Studies, v. 36, n. 1, p. 23-37, 2008. 
LEVINTHAL, Daniel; MYATT, Jennifer. Co-evolution of capabilities and industry: the evolution of mutual fund processing. Strategic Management Journal, v. 15, n. S1, p. 45-62, Winter 1994.

LEWIN, Arie Y.; LONG, Chris P.; CARROLL, Timothy N. The coevolution of new organizational forms. Organization Science, v. 10, n. 5, p. 535-550, 1999.

LEWIN, Arie Y.; VOLBERDA, Henk W. Prolegomena on coevolution: a framework for research on strategy and new organizational forms. Organization Science, v. 10, n. 5, p. 519-534, 1999.

MALIK, Omar R.; KOTABE, Masaaki. Dynamic capabilities, government policies, and performance in firms from emerging economies: Evidence from India and Pakistan. Journal of Management Studies, v. 46, n. 3, p. 421-450, 2009.

MARTINS, Renata. Etanol e biodiesel: inovação tecnológica e a política nacional de ciência e tecnologia. Informações Econômicas, v. 40, n. 11, p. 21-32, 2010.

MCKELVEY, Bill. Perspective-quasi-natural organization science. Organization Science, v. 8, n. 4, p. 351-380, 1997.

MILES, Matthew B.; HUBERMAN, A. Michael. Qualitative data analysis: a source book of new methods. Bervely Hills, CA: Sage, 1984.

MKANDAWIRE, Thandika. Transformative social policy and innovation in developing countries. The European Journal of Development Research, v. 19, n. 1, p. 13-29, 2007.

NELSON, Richard R. Co-evolution of industry structure, technology and supporting institutions, and the making of comparative advantage. International Journal of the Economics of Business, v. 2, n. 2, p. 171-184, 1995.

NELSON, Richard R.; WINTER, Sidney G. An evolutionary theory of economic change. Cambridge, MA: Harvard University Press, 1982.

RIM, Myung-Hwan; CHOUNG, Jae-Yong; HWANG, Hye-Ran. The sources and directions of technological capability accumulation in the Korean semiconductor industry. ETRI Journal, v. 20, n. 1, p. 55-73, 1998.

RODRIGUES, Suzana; CHILD, John. Co-evolution in an institutionalized environment. Journal of Management Studies, v. 40, n. 8, p. 2137-2162, 2003.

RODRIK, Dani. Taking trade policy seriously: export subsidization as a case study in policy effectiveness. In: LEVINSOHN, James; DEARDORFF, Alan K.; STERN, Richard M. (Ed.). New direction in trade theory. Michigan: University of Michigan Press, 1995.

SAVIOTTI, Pier P.; PYKA, Andreas. Economic development by the creation of new sectors. Journal of Evolutionary Economics, v. 14, n. 1, p. 1-35, 2004.

ŠVARC, Jadranka; PERKOVIC, Juraj; LAZNJAK, Jasminka. Unintended consequences of innovation policy programmes: social evaluation of technological projects programme in Croatia. Innovation: Management, Policy \& Practice, v. 13, n. 1, p. 77-94, 2011. 
SUHOMLINOVA, Olga. Toward a model of organizational co-evolution in transition economies. Journal of Management Studies, v. 43, n. 7, p. 1537-1558, 2006.

TEUBAL, Morris. What is the systems perspective to Innovation and Technology Policy (ITP) and how can we apply it to developing and newly industrialized economies? Journal of Evolutionary Economics, v. 12, n. 1, p. 233-257, 2002.

YANG, Dong. How does knowledge sharing and governance mechanism affect innovation capabilities? - from the coevolution perspective. International Business Research, v. 4, n. 1, p. 154-157, jan. 2011.

Samuel Façanha Câmara é professor adjunto e docente permanente do Programa de Pós-Graduação em Administração da Universidade Estadual do Ceará (Uece). Possui doutorado em economia pela Universidade Federal de Pernambuco (UFPE) e pós-doutorado em gestão da inovação pela Escola Brasileira de Administração Pública e de Empresas da Fundação Getulio Vargas (FGV/Ebape). E-mail: samuel. camara@uece.br.

Alexander Brasil é bacharel em administração pela Universidade Federal do Ceará (UFC) e mestre em administração pela Universidade Estadual do Ceará (Uece). E-mail: alexander_brasil@yahoo.com.br. 